\title{
Online and print newspapers in Europe in 2003. Evolving towards complementarity
}

\author{
RICHARD VAN DER WURFF, EDMUND LAUF, \\ AUKSĖ BALČYTIENĖ, LEOPOLDINA FORTUNATI, \\ SUSAN L. HOLMBERG, STEVE PAULUSSEN \\ and RAMÓN SALAVERRÍA
}

\section{Abstract}

This article assesses online newspapers in Europe from a media evolutionary perspective, ten years after the introduction of the World Wide Web. Comparing print and online front pages of 51 newspapers in 14 countries in 2003, we argue that online newspapers complement print newspapers in modest ways. Online, publishers put more emphasis on service information, offer additional news items, that nonetheless report on similar topics in similar ways, and add personal interactivity, content selectivity and realtime news to the print news offering.

One subset of online newspapers charges for services, and offers more content and personal interactivity. Another, partly overlapping subset offers more original news; in a short and anonymous format. Overall, however, online newspapers in Europe make up a heterogeneous group, suggesting that online newspapers still have to find their definite form and role in the European news market.

Keywords: media evolution, online newspapers, print newspapers, Europe

\section{Online newspapers in Europe}

The development of online newspapers is a major, yet unfinished experiment in innovation in the newspaper industry. It has caught the imagination and attention of scholars and experts, who advanced enthusiastic views of how the Internet could improve the provision of news and debate in society, as well as gloomy predictions of how print newspapers and traditional newspaper publishers would become obsolete. At a more concrete level, the development of online newspapers is a continuous search for ways to use Internet technology to improve existing practices of news production and consumption. 
This paper assesses how newspaper publishers and editors have dealt with these challenges. Our focus is on serious European newspapers in 2003, ten years after the introduction of the World Wide Web. Our approach is media-evolutionary and comparative. We investigate how publishers position online newspapers on the intermedia news market in relation to print newspapers. Our guiding hypothesis is that new media initiate a media evolutionary process in which old and new media alike are forced to adapt to each other and find new and different niches (Dimmick and Rothenbuhler, 1984; Lehman-Wilzig and Cohen-Avigdor, 2004). What particular niches old and new media, and in our case, print and online newspapers, eventually occupy is a question for empirical research. Beginning to address this question, we investigate in this paper to what extent print and online newspapers offer the same or different types of editorial and non-editorial content and services.

Building on previous studies that investigated online newspapers in individual countries in the late 1990s, this study describes in detail the front pages of 51 print and online newspapers in 14 European countries in 2003. We compare the types of content and editorial information offered in print and online newspapers and assess so-called Internet features. We attempt to construct a typology of online newspapers that concisely expresses different ways in which online newspapers are developing. And we assess whether observed differences are indicative for underlying business models, or related to the varying newspaper cultures in Europe.

The adopted approach enables us to make a qualitative comparison between online newspapers in the late 1990s and early 2000s, providing some understanding of how the media-evolutionary process has developed in that period. Hopefully our results and method provide a baseline for future studies that chart the continued evolution of print and online newspapers more systematically.

\section{Media evolution of print and online newspapers}

Different media occupy different niches in the intermedia news market (Dimmick, 2003). They perform (at least partly) different functions, serve different needs, and/or offer different contents and services. When a new medium enters the market, argues the media-evolutionary approach proposed by Lehman-Wilzig and Cohen-Avigdor (2004) and Stöber (2004), that new medium needs to find its own niche by acquiring its own distinctive characteristics and unique selling points (e. g., in terms of formats, contents, functions, or usages). In theory it is possible that a new medium outperforms an older medium on all relevant dimensions and thereby makes that medium obsolete (Lehman-Wilzig and Cohen-Avigdor, 
2004). Yet in practice few, if any, media have been completely replaced. In 1913, this already induced the German editor-in-chief Riepl to argue that new media do not replace existing media but rather force them to adapt and find different niches (in: Glotz, 2004).

Following this media evolutionary approach, we consider the Internet as emerging news medium that needs to find its place on the intermedia news market, next to other news media. We observe that online news providers experiment with Internet-specific opportunities for interactivity, selectivity, multimedia, and easy updating to provide attractive online news and advertising services. We expect that these emerging online services take over some functions of print newspapers and challenge publishers to (re)consider and (re)develop the characteristics, unique selling points, and preferred uses of print newspapers.

This, however, is only part of the story. The low entry barriers of the Internet enable publishers and broadcasters to become online news providers themselves at a relatively low cost. This implies that from very early onwards, competing 'old' and 'new' media are developed by partly the same media organizations. The shared digital characteristics of modern-day 'old' and 'new' media, moreover, enable media organizations to transfer traditional media almost entirely onto the Web, potentially turning the Internet into a multimedia distribution platform, or metamedium (Lehman-Wilzig and Cohen-Avigdor, 2004), rather than a medium by itself, which we define as a historical combination of a particular media technology with its own particular contents, functions, media formats, providers, and usages (McQuail, 2005: 24, 331). How print and online newspapers actually develop under these conditions as complementing (differentiated) or similar (replicated) news services and what niches they consequently occupy, depends on (the interactions between) publishers' strategic choices and experiments, media-technological and business-economic constraints, user needs and perceptions, and relevant policies (Stöber, 2004). This is therefore primarily a question for empirical research that is addressed in this paper.

\section{Unbundling}

Print newspapers developed, for good economic reasons, into familiar bundles of different types of content (Sparks, 2003), such as political news, weather forecasts and classified ads. These bundles offer something for almost every one and every taste. They are produced and sold on a relatively large scale, which reduces average costs per issue to acceptable proportions. The Internet threatens this practice of bundling and mass production (Sparks, 1999). Online, it is technically and economically feasible to unbundle the newspaper and to distribute different 
combinations of what used to be newspaper content to different audiences. Examples include personalized news services that provide individual readers with specifically requested news articles, and electronic markets and job sites that replace newspapers' classified and employment ads pages. These unbundled products, customized for specific needs and audiences, generally serve customer needs better than traditionally bundled products (Evans and Wurster, 2000; also Weber, 2006).

Of course, the Internet offers publishers and editors opportunities to respond to these challenges, too. Publishers can as easily start online services as any new online competitor. Some shovel (part of) the print edition online to promote the print paper or serve customers that could not be served cost-effectively before. Others use the Internet to build closer relationships with readers (Cowen, 2001; Mings and White, 2000; Peng, Tham, and Xiaoming, 1999). Some technological-optimist observers even envisage that the emerging Internet forces publishers and editors to change their news services completely (Lasica, 1996; see also Bardoel, 1996). According to those observers, the media logic of the Internet demands interactivity, immediacy, personalization, and multimedia. The traditional role of newspapers as gatekeeper is predicted to be finished. Their new role would be to facilitate communications between readers and between readers and journalists.

Most online newspapers in the late 1990s, however, did not come close to these enthusiastic expectations (Boczkowski, 2002; Massey and Levy, 1999). Research at that time showed that newspapers tended to be reduced but otherwise exact copies of print editions (Neuberger, Tonnemacher, Biebl, and Duck, 1998; Saksena and Hollifield, 2002; Zürn, 2000) with little, if any, interactivity, hyperlinking, multimedia, or realtime information (Kenney, Gorelik, and Mwangi, 2000; Massey and Levy, 1999; Schultz, 1999). These findings underline the limitations of technologically-based optimism and focus attention on the business-economic constraints of media evolutionary processes (Lehman-Wilzig and Cohen-Avigdor, 2004; Stöber, 2004).

\section{Business models}

A major reason why online newspapers in the late 1990s looked very much like print newspapers is an economic one. Providing special online features and services is costly, yet most publishers find it difficult to earn sufficient online revenues to cover online running expenses, let alone recover online investments (Brook, 2006; Harvey, 2004). Repurposing print content under these circumstances is a cheap solution to get online services started. In the longer term, however, publishers need to develop online services that improve the competitive position of the newspaper 
(Chyi and Lasorsa, 2002; Deleersnyder, Geyskens, Gielens and Dekimpe, 2002). This makes the search for viable online business models a key issue for publishers.

One business model considered in the literature is the paid news, or news portal model (Picard, 2000), where publishers sell online news and value added news services to users that are willing to pay for these services. Selling news is usually recommended for a few newspapers that operate in the high-end financial/business segment (Hayward, 2002). Yet studies indicate that general online newspapers, too, may earn money by selling access to searchable archives and customized news (Ihlström and Palmer, 2002).

Another business model is the e-commerce model, adopted by some local newspapers in the USA that attempt to develop the online newspaper into a local e-commerce platform (Chyi and Sylvie, 2000). This model is less useful for newspapers in Europe where readers perceive the newspaper primarily as a news provider (Ihlström and Palmer, 2002). The sales of non-news products, currently limited to small-scale activities as the sales of crossword puzzles, horoscopes, and (personalized) health and beauty tips (Harvey, 2004), may nevertheless develop into an additional revenue source for publishers, especially when publishers develop brand-extensions (INMA, 2006).

A third business option is to consider online newspapers as a customer relationship management (CRM) tool (see Grant and Schlesinger, 1995). Online newspapers may strengthen newspaper brands, attract new print subscribers (Chyi and Sylvie, 2000; Harvey, 2004) and boost print subscriber loyalty. They can also be used to collect valuable reader input and information, which in turn enables better-targeted advertising and sales of other products to readers. In this CRM model, online newspaper costs are justified as marketing expense and in time hopefully covered by increasing print newspaper, non-news sales, or print and online advertising revenues.

Online advertising is the most frequently used source of revenue. It can contribute to all of the above-mentioned business models and, besides, is the most important if not only revenue source for publishers that are still experimenting with online newspapers. Online advertising revenues grow rapidly, but nevertheless remain small; in the vicinity of $5 \%$ of total advertising revenues for US newspapers in 2005 (Newspaper Association of America, 2006; also Harvey, 2004).

\section{News market characteristics}

The choice for a business model and for revenue sources has implications for the types of content and services on offer. Also, differences in news- 
paper culture and market conditions may play a role. Newspaper penetration and reader loyalty are traditionally higher in the North of Europe than in the Middle, and lowest in the South (Gustafsson and Weibull, 1997). Internet penetration and the shares of newspapers and Internet in advertising revenues are likewise highest in the North and lowest in the South (Van der Wurff and Lauf, 2005b). This suggests that publishers in the North have better opportunities to develop online editions, whereas newspapers in the South face stronger threats. Whether and how these differences translate into the development of online newspapers is an open question.

\section{Research questions}

We argue from a media evolutionary perspective that the emergence of the Internet challenges publishers and editors to reconsider and redevelop print and online newspapers as more or less complementary and bundled offerings of content and services. This is an ongoing process, guided by old and new media organizations' experiments and strategies as well as by technological, economic, policy, and user constraints. Research in the late 1990s showed that, at that time, online newspapers were very similar to print newspapers. Reflecting our experiences in different European countries some years later, we expect to find that media evolution has continued and that publishers start to make more use of the typical features of the Internet to differentiate online from print newspapers. Moreover, we expect to find that different newspapers experiment with different approaches and business models, partly reflecting the different market conditions under which publishers operate across Europe. To examine these expectations, we investigate:

RQ1. To what extent and in what way do online newspapers complement rather than replicate print newspapers in Europe?

RQ2. Is it possible to distinguish different types of online newspapers in Europe that complement print newspapers in different ways and degrees?

RQ3. Can differences between online newspapers be attributed to underlying business models or news market conditions?

\section{Method}

We use data from a content analysis of 51 national, general-interest newspapers from 14 different countries in Europe. The content analysis was carried out by researchers from the newspaper working group of a COST funded research network on the impact of the Internet on mass 
media (COST Action A20) in 2003 and 2004. Since no comparative study of print and online newspapers in Europe was available at that time, we decided to take a relatively broad and inductive approach, selecting elements for analysis that were considered useful on the basis of previous research or our own national experiences, and including as many countries as possible. To make the analysis feasible and comparable across countries and media, we limited the material to front pages of serious national newspapers ${ }^{1}$, as they were published, in print or online, on October 8,2003 , which was chosen as a fairly standard news day in the selected countries. The main international news item on that day was Schwarzenegger's election as Governor of California.

\section{Sample}

We focus on the main national or supra-regional, general-interest, paidfor newspapers in Europe. Specialist newspapers (e. g., sports newspapers), tabloids, regional newspapers, and freesheets are excluded. These newspapers offer different types of content and cannot easily be compared with the main serious national newspapers that we study.

We include newspapers from 14 different countries: the Dutch-speaking part of Belgium (Flanders), Denmark, Finland, Germany, Greece, Ireland, Italy, Lithuania, the Netherlands, Portugal, Spain, Sweden, Switzerland, and the United Kingdom. These countries differ considerably in newspaper reading culture (Gustafsson and Weibull, 1997) and newspaper market characteristics (Van der Wurff and Lauf, 2005b). Per country, we select three to five newspapers with the largest circulation ${ }^{2}$. The selected newspapers represent, in quantitative and qualitative terms, the traditional serious national press in each country and, as far as practically possible, across Europe.

To be able to compare print and online newspapers we follow other studies and analyse front pages (see Bridges and Bridges, 1997; Ha and James, 1998; Kenney et al., 2000; Li, 1998; Schoenbach, 1997). The front page is the primary editorial page where the most important news is presented and other parts of the newspaper are made accessible via pointers (hyperlinks or other references). The front page presents the newspaper to (potential) readers. It shows what editorial and other content items are considered important and attractive. Front pages therefore give us a good understanding of the respective strengths of print and online newspapers as the providers want to show and emphasize them.

We analyse the print and online front pages as they were published on October 8, 2003. Online newspapers were sampled twice on this day, so that we could assess the extent of content updating during the day. The 
selected sample times, 9:00 am and 19:00 pm, were chosen as the times when print editions of morning and evening papers were available, too.

Previous research has shown that the structure and design of newspapers and the provision of various Internet-specific features (such as multimedia and interactivity) are relatively constant over time ( $\mathrm{Li}, 1998$; Schultz, 1999). A one-day sample enables us to describe these elements reliably. News, in contrast, varies daily, which makes a one-day sample inappropriate to give a representative assessment of editorial content in newspapers. Our aim, however, is more modest in that we are interested in (differences and similarities) in the editorial selections made for print and online newspapers, given a day's supply of newsworthy events. Since the sampling day, October 8, 2003, was a fairly standard news day in the selected countries, we argue that differences in editorial approach, if existing, are reflected in the choice and presentation of important news items on the sample day.

The analysis of editorial items focuses on the 15 most important news items that are presented or start on the front page. This is because print and online editions generally offer very different numbers of news items. The most important items are those that occupy the largest space. Additional selection criteria include the presence of illustrations, and a position at the top of the front page. If news items are continued on secondary pages, these continuations are included in the content analysis.

\section{Measurements}

We analyse print and online front pages on 14 dimensions, derived from previous studies (cited below). Each dimension refers to a particular and comprehensive set of options that providers may include in their newspaper bundles. The content dimension, for example, encompasses eight different types of content that newspapers may offer (Lin and Jeffres, 2001). These are: news, self-promotion ${ }^{3}$, service information ${ }^{4}$, entertaining and play items (such as cross word puzzles), interaction and communication elements (e.g., search engines, letters to the editor, and discussion forums), display advertising, classified ads, and employment ads. Six news item dimensions additionally encompass over 30 news item options that may or may not be added to newspaper bundles (Bridges and Bridges, 1997; Li, 1998; McQuail, 2005; Singer, 2001; Sparks, 2003). These options include different topics, geographic orientations, types of illustrations, types of sources, story formats, and types of authors. Internet feature dimensions, thirdly, describe 25 frequently investigated Internet features (Ha and James, 1998; Jankowski and Van Selm, 2000; Kenney et al., 2000; Massey and Levy, 1999), organized on seven dimensions: user-user interaction, user-producer interaction, content selection, per- 
sonalization, the use of hyperlinks, multimedia, and the provision of real-time news. More information on these options is offered in the results section.

We use these 14 dimensions in different ways. First, we note which content options, news item option and Internet-specific features are available, that is, present on the front page, regardless of number or space. Next, we assess the relative importance of content and news item options by estimating the proportion of front-page space devoted to content types and the relative number of news items with particular characteristics. Dividing the number of available options on a dimension by the total number of possible options gives indices for content and news item variety. Likewise, Internet feature indices indicate on a scale from 0 to 1 how many Internet features are offered. Complementarity indices, finally, indicate how many options on a particular dimension are added by the online edition to the print offer. These scores are defined as the number of options available in the online but not the print edition, divided by all possible options on a dimension. Since Internet-specific features are only assessed for online editions, no corresponding complementarity indices for Internet features are estimated.

\section{Content analysis: Reliability}

The codebook for the content analysis (Van der Wurff and Lauf, 2005a) was developed in cooperation with all involved researchers. In total, 137 variables were coded for each online newspaper and a subset of 88 variables for print newspapers. Several trial codings were performed and the codebook was improved based on the results of these trial codings. Before the final coding, a reliability test was done. Given that we work with an international team of researchers, we use material in a common and (for most coders) foreign language, and assess reliability by comparing the coding of individual coders with a master coding (as recommended by Peter and Lauf, 2002). Average reliability equalled .94 (following Holsti's formula), ranging between .84 and 1.00 for all but a few variables.

To improve reliability further, variables with lower reliability were used as components of aggregated variables or indices. Considering in addition that reliability was tested with English language newspapers that were unfamiliar to most coders, these estimates indicate that coding is reliable.

\section{Print and online content}

Newspapers are bundles of different types of content. News, self-promotion and display advertising are the staple content categories of print 
Table 1. Types of content on print and online front pages (means).

\begin{tabular}{|c|c|c|c|c|c|c|}
\hline & \multicolumn{3}{|c|}{ Availability } & \multicolumn{3}{|l|}{ Space } \\
\hline & Print & Online & & Print & Online & \\
\hline News & 100 & 100 & & 76 & 64 & $* *$ \\
\hline Display advertising & 75 & 92 & $\mathrm{o}$ & 8 & 7 & \\
\hline Self-promotion & 94 & 100 & & 14 & 13 & \\
\hline Interaction/communication & 59 & 100 & ** & 1 & 6 & $* *$ \\
\hline Service information & 61 & 98 & $* *$ & 1 & 6 & $* *$ \\
\hline Entertainment/play & 29 & 82 & ** & 0 & 2 & $* *$ \\
\hline Job advertising & 14 & 61 & $* *$ & 0 & 1 & $* *$ \\
\hline Classified ads & 31 & 67 & $* *$ & 0 & 1 & $* *$ \\
\hline
\end{tabular}

Notes: Availability $=$ average $\%$ of front pages mentioning (via pointer) or displaying content type. Space $=$ average $\%$ of front page space devoted to content type. Number of newspapers $=51$. T-test significant at $* * \mathrm{p}<.001$ or $^{\circ} \mathrm{p}<.05$ where indicated.

and, according to our study, also online newspapers (Table 1). The main difference between print and online newspapers concerns other content categories.

First, and very visibly, online front pages include many more pointers (i. e. hyperlinks and references to content items on secondary pages). In terms of size, almost $30 \%$ (table not shown) of online front pages is used for pointers rather than for substantive content items. In print, similar pointers (like a table of contents) take up less than 3\%. Another important difference is that online front pages more frequently present or mention (via a pointer) interaction and communication elements, service information, entertaining and play items, classified ads, and employment advertisements.

The attention for additional content categories on online front pages reduces the amount of space available for news, which is the type of content that takes up the largest space on all front pages. Display advertising and self-promotion come second and third in print and online newspapers. Percentages of space devoted to these and other content categories (shown in Table 1) confirm that online newspapers provide more different types of content on front pages than print front pages.

\section{Original online news?}

Some scholars have argued that journalists in the online world should expand their task and in addition to, if not as a replacement of their traditional mediating function, should facilitate information searches of readers and make readers more active (and critical) (Bardoel, 1996; Deuze, 2003; Kenney et al., 2000; Quinn and Trench, 2002: 15). Hyper- 
links and, since a few years, weblogs are the proverbial tools for journalists that aim to develop such a new journalistic approach (Dimitrova, Connolly-Ahern, Williams, Kaid, and Reid, 2003; Matheson, 2004). Research in the late 1990s, however, presented a different picture. Online journalists tended to produce shovelware, "taking information generated originally for a given print paper's edition, and deploying it virtually unchanged onto its website" (Boczkowski, 2002: 274). These journalists simply did not have the time to interact with readers, to add hyperlinks to news stories, or to rework print articles in a news item style that is considered more appropriate for online news (O'Sullivan, 2005).

In 2003, this situation has changed to some extent. Approximately $35 \%$ (table not shown) of the most important online news items is exclusive to the online edition, although some items might be published in print the next day. Moreover, $22 \%$ of items that are found in both editions have different content in print and online, and $29 \%$ has different illustrations or headlines. Consequently, not more than $31 \%$ of investigated items per online newspaper are completely identical to a print item.

\section{Print and online news items}

Although print and online front pages do not provide identical news items, they nevertheless provide remarkably similar news items. Comparing the relative importance of 32 news item options divided over six dimensions, we hardly find any significant differences between print and online editions.

Topics. Print and online newspapers provide similar proportions of political and economic news, other serious news (on social, health, welfare, nature, environment and physical planning issues), safety- and injury-related items (on crime, terrorism, war, accidents and other sudden events), culture-related news (on arts, science, education, and media), human-interest news, and sports news.

Illustrations. Print and online newspapers do not differ in the extent to which they add photos, infographics, or entertaining graphics to news items.

Geography. Print and online newspapers provide similar proportions of local news, domestic news, transnational news (i. e., news on one's country in relation to other countries or international organizations or developments), and international or foreign news.

Sources. Similar proportions of news items in print and online newspapers refer to four different types of sources, namely the (print or online) counterpart, other media, news agencies, and standard journalist sources (like press conferences and spokespersons). 
Formats. Online newspapers provide slightly more colour-writing items (that emphasize personal experiences of a reporter or the public, or present a person, group or organization) than print newspapers, but are similar in the use of other formats, including briefs, caption stories, factual news stories, commentary and editorials, analysis, interviews, original documentation, columns, and collection of quotes from other media.

Authorship. The main difference between print and online news items that we found concerns the relative importance of different types of authors. Online front pages include more news items written by news agencies $(13 \%$ instead of $3 \%$; t-test significant at $\mathrm{p}<.01)$ and less news items written by journalists $(61 \%$ instead of $73 \% ; p<.05)$. Other types (anonymous news items and items written by external authors) are again provided in similar proportions.

Availability of options. When we consider the availability rather than the relative importance of news item options, we find slightly more, but still relatively few differences. More online than print front pages include at least one foreign news item (available in $94 \%$ and $80 \%$ respectively; t-test significant at $\mathrm{p}<.05$ ). Likewise, online readers are more likely to find at least one colour-writing item (available in $45 \%$ of online and $24 \%$ of print front pages; $p<.05$ ) and less likely to find at least one caption story (available in $29 \%$ of print and $12 \%$ of online newspapers; $\mathrm{p}<.05)$. Thirdly, online newspapers more frequently include at least one item written by a news agency (available in 53\% of online and $29 \%$ of print newspapers; $p<.05$ ). Finally, more online newspapers refer at least once to the print edition as a source than vice versa $(22 \%$ and $4 \%$ respectively; $\mathrm{p}<.01$ ).

\section{Online complementarity}

Given these findings, it is not surprising that online newspapers complement print newspapers better in content than in news item terms (see Table 2). The online complementarity index for front-page content signals that online newspapers add, on average, 2.5 content categories to the print offering ${ }^{5}$. The complementarity indices for news item characteristics are considerably lower (see again Table 2). They indicate that online front pages add between $9 \%$ and $17 \%$ of available options to the print news item offering. In practice, this means that online newspapers add one option on the format dimension and fewer options on the other news item dimensions to the print offer. Apart from that, online newspapers complement print editions in varying and multiple ways. There are no typical online news item options that are consistently added by online newspapers to most, if not all print editions. 
Table 2. Variety and complementarity of print and online newspapers (means).

\begin{tabular}{|c|c|c|c|c|c|}
\hline & \multicolumn{3}{|c|}{ Variety Index } & \multirow{2}{*}{$\begin{array}{l}\text { Complementarity } \\
\text { Index }\end{array}$} & \multirow[t]{2}{*}{ \# of options } \\
\hline & Print & Onl & & & \\
\hline Front page content & .58 & .88 & $* *$ & .32 & 8 \\
\hline \multicolumn{6}{|l|}{ News item } \\
\hline Topic & .71 & .75 & & .15 & 6 \\
\hline Geographic orientation & .73 & .77 & & .12 & 4 \\
\hline Illustration & .56 & .48 & & .09 & 3 \\
\hline Source & .49 & .59 & $\mathrm{o}$ & .17 & 4 \\
\hline Format & .27 & .26 & & .10 & 11 \\
\hline Author & .53 & .62 & o & .17 & 4 \\
\hline
\end{tabular}

Number of newspapers $51 \quad 51 \quad 51$

Notes: Variety index = average proportion of possible options actually offered. Complementarity index $=$ average proportion of possible options only available online. Multiplying an index with the \# of options in the last column gives the number of options that are, on average, available in print or online, or unique to the online edition. Number of newspapers $=51$. T-test significant at $* * \mathrm{p}<.001$ or $^{\circ} \mathrm{p}<.05$ where indicated.

\section{Internet-specific features}

Another way in which online newspapers can complement print newspapers, intensively discussed by many scholars, is by offering "Internetspecific features such as two-way communication, searchable databases, real-time data transmission, hyperlinking, and multimedia presentation" (Chyi and Lasorsa, 2002: 104; see also Chyi and Sylvie, 1998; Deleersnyder et al., 2002). Research in the late 1990s found that Internet-specific features were only sparsely used. Interactivity, hyperlinking, multimedia and real-time information had to be searched for with a magnifier (Kenney et al., 2000; Massey and Levy, 1999; Schultz, 1999). In 2003, the same conclusion still holds for multimedia and personalisation. Other features, in particular content selection options, user-user interaction, and news updates, are better developed.

Content interactivity refers to the degree to which content producers empower users to select their own content (Massey and Levy, 1999). Basic content selection options such as search engines and online archives are made available by most online newspapers (Table 3 ). Personalisation and hyperlinking options on the other hand are not well developed. Few online newspapers offer geographical or language editions, or allow users to personalize the online front page in content or technical terms. Hyperlinks, thirdly, point mostly to other items in the same website ( $91 \%$ of all hyperlinks per outlet). They do not lead users outside the online newspaper to other websites (see also Dimitrova et al., 2003). 
Table 3. Internet-specific features in online newspapers (means).

\begin{tabular}{|c|c|c|}
\hline & Index & Availability \\
\hline Content selectivity & .87 & \\
\hline Online newspaper search option & & 88 \\
\hline Archive & & 86 \\
\hline Personalisation & .12 & \\
\hline Language editions & & 10 \\
\hline Geographical editions & & 14 \\
\hline Personalization of front page in content terms & & 14 \\
\hline Personalization of front page in technical terms & & 10 \\
\hline Hyperlinks & .50 & \\
\hline Hyperlinks to same online newspaper & & 75 \\
\hline Hyperlinks to other online outlet & & 25 \\
\hline User-producer interaction & .30 & \\
\hline Addresses for journalists & & 14 \\
\hline Author e-mail mentioned in item & & 18 \\
\hline Invitation to comment & & 43 \\
\hline Item-specific invitation to comment & & 25 \\
\hline Poll/user survey & & 37 \\
\hline Item-specific poll & & 16 \\
\hline Letters/messages to the editor & & 55 \\
\hline User-user interaction & .42 & \\
\hline Item forward option & & 67 \\
\hline Chat room or forum & & 49 \\
\hline Item-specific forum & & 10 \\
\hline Multimedia & .06 & \\
\hline Real-time news & .42 & \\
\hline Breaking news section & & 35 \\
\hline News item time stamp & & 41 \\
\hline Front page time stamp & & 20 \\
\hline News item turnover index $>1 / 3$ & & 71 \\
\hline News item turnover index $>2 / 3$ & & 41 \\
\hline
\end{tabular}

Notes: Index $=$ average proportion of possible Internet features actually offered. Availability $=$ average $\%$ of online newspapers offering a feature. Number of newspapers $=51$

Content interactivity expresses the consultation logic of the database. Interpersonal interactivity rather expresses the logic of conversation: two-way, interactive communication between users, or users and journalists (Kluver, 2002; Li, 1998; Schultz, 1999). General features that stimulate personal interactivity, invitations to comment, opinion polls, discussion forums and an option to forward news items, are provided by oneto two-thirds of online newspapers (Table 3). More sophisticated and laborious options, e-mail addresses for individual journalist, opinion polls and forums dedicated to specific news items, are available in but a 
few online newspapers. Perhaps most striking is that more than half of the online newspapers offers or mentions users' letters and messages on the front page. These results signal that user-generated content is important for online newspapers. Overall, however, personal interactivity is less well developed than content interactivity.

Multimedia remains very limited. Not more than 6 online newspapers ( $12 \%$ of our sample) add an audio file to one or more important news items, and not more than 3 online newspapers (6\%) add a movie file. Only one outlet offers both. No outlet at all adds animations to one or more important news items.

Finally, online newspapers do relatively well as providers of frequently updated or real-time news. Frequent updates are considered as one of the strong points of online news (Jankowski and Van Selm, 2000). Onethird of the online newspapers has a breaking news section. Two-fifth of the online newspapers emphasizes the frequency of updating by adding time stamps to important news items. General information on when the front page was last updated is only provided by one-fifth of online outlets. These time stamps suggest that at the time of data collection, online front pages had a median age of 38.5 minutes. The most important indicator for the speed with which online newspapers update their news, however, is the turnover in news items during the day. The average news item turnover index equals .57 on a scale from 0 to 1 . This indicates that, on average, $57 \%$ of the 15 most important news items in the evening edition are completely new, whereas the remaining items were already part of the most important items in the morning edition.

\section{A typology of online newspapers?}

The average online newspaper complements the print counterpart in modest ways. It provides additional types of content on front pages, such as interaction and communication features, and service information. It also offers different news items than the print edition, but these news items report on similar topics in similar ways. In addition, the average online newspaper offers content selection options, general (rather than item-specific) user-user interaction features, and regularly updated news. Multimedia and more sophisticated types of content and personal interactivity (external hyperlinks, personalization options, journalist e-mail addresses, item-related discussion forums) remain limited.

Underneath these averages, there obviously exist differences between online newspapers. For example, we can distinguish a larger group of 36 newspapers that use between 1 and 3 news item formats from a smaller group of 15 newspapers that use between 4 and 7 formats. The latter group complements the print counterpart better by adding more unique 
formats to the print edition than the former group. Similar conclusions hold for most other investigated dimensions. However, further analysis shows that variation on one dimension is only marginally related to variation on other dimensions ${ }^{6}$. It is not possible to distinguish between online newspapers that consistently provide more and less variety, or between online newspapers that provide variety on clearly different dimensions.

\section{Frequently updated versus shovelware newspapers}

The only consistent classification that emerges from the data and that intuitively makes sense is a distinction between frequently updated and shovelware newspapers. Frequently updated newspapers provide relatively many original news items: online-only news items that are not published in the print edition of the same day. Shovelware newspapers, in contrast, copy relatively many print items without modifications to the online edition.

Further comparison of frequently updated and shovelware newspapers shows that they are similar in many respects. The main differences between frequently updated and shovelware newspapers concern (a) the proportion of front page space devoted to different content categories and (b) the proportion of news items with specific characteristics (see Table 4). These

Table 4. Frequently updated versus shovelware online newspapers (means).

\begin{tabular}{|c|c|c|c|}
\hline & $\begin{array}{l}\text { Frequently } \\
\text { updated }\end{array}$ & Shovelware & \\
\hline \multicolumn{4}{|l|}{ Internet-specific features } \\
\hline Real-time news index & .54 & .39 & o \\
\hline News item turnover index & .77 & .52 & o \\
\hline \multicolumn{4}{|l|}{ Percentage of front page space devoted to } \\
\hline News & 54 & 66 & o \\
\hline Service information & 9 & 5 & $*$ \\
\hline Display advertisements & 12 & 6 & o \\
\hline Pointers & 38 & 26 & o \\
\hline \multicolumn{4}{|l|}{ Percentage of news items } \\
\hline With international news & 45 & 25 & $* *$ \\
\hline In brief format & 38 & 5 & $* *$ \\
\hline In caption story format & 4 & 1 & o \\
\hline In factual news story format & 51 & 73 & o \\
\hline Written by journalist & 21 & 71 & $* *$ \\
\hline Anonymous & 60 & 13 & $* *$ \\
\hline Based on standard journalist sources & 50 & 88 & $* *$ \\
\hline Number of newspapers & 10 & 41 & \\
\hline
\end{tabular}


differences suggest that original news items in frequently updated newspapers consist primarily of short and anonymous items, including a few caption stories. Shovelware newspapers, in contrast, copy a considerable amount of factual news stories, written by journalists and based on standard journalist sources. Since short stories take up less space on the front page, frequently updated newspapers are able to devote more space to pointers and, counting both pointers and content items, use more space for service information and advertisements than shovelware newspapers.

\section{Business models and news market characteristics}

The types of content and services that online newspapers offer, and the conditions under which this offer is made available, in theory reflect the business models that providers have adopted. The literature review identified three online business models. An analysis of relevant online front-page characteristics suggests that 14 online newspapers in our sample tend towards a paid content model. These newspapers offer and sell (access to) relatively many content services, including news archives, PDF replicas, and mobile news services. A total of 11 newspapers tend towards a CRM (Customer Relationship Management) model. These CRM newspapers require registration for access to the online newspaper itself, to news archives and/or to classified ads databases. Registration enables providers to collect user data, which is a cornerstone of the CRM model. The remaining 26 newspapers show no distinctive characteristics. They use similar proportions of the front page for display advertising and self-promotion as the paid and CRM newspapers, and do not differ in the extent to which they use the same masthead (in wording and design) as the print edition. We assume that the publishers of these 26 newspapers have not yet adopted a definite business model. Finally, front-page analysis suggests that no newspapers tend towards the e-commerce model.

In a cross-European study we may additionally expect to find differences between online newspapers from the North, Middle, and the South of Europe that reflect underlying differences in news market characteristics (see Table 5). Differences in newspaper reach Internet penetration and the share of newspapers in advertising revenues suggest that newspaper publishers in the North; in our sample: Finland, Sweden, Denmark, have better opportunities to develop online editions than publishers in the Middle; Belgium, Germany, Ireland, Lithuania, Netherlands, Switzerland and the UK; or the South; Greece, Italy, Portugal and Spain. 
Table 5. News market characteristics.

\begin{tabular}{lllll}
\hline & $\begin{array}{l}\text { Newspaper } \\
\text { reach }\end{array}$ & $\begin{array}{l}\text { Newspaper } \\
\text { ad share }\end{array}$ & $\begin{array}{l}\text { Internet } \\
\text { penetration }\end{array}$ & $\begin{array}{l}\text { Opportunities } \\
\text { scale }\end{array}$ \\
\hline North & & & & \\
$\quad$ Sweden & 88 & 48 & 66 & 67.5 \\
$\quad$ Finland & 87 & 50 & 55 & 64.0 \\
$\quad$ Denmark & 80 & 42 & 67 & 63.0 \\
Middle & & & & \\
$\quad$ Netherlands & 71 & 41 & 68 & 59.9 \\
Ireland & 59 & 60 & 57 & 58.7 \\
Germany & 76 & 44 & 46 & 55.2 \\
Switzerland & 76 & 46 & 32 & 41.3 \\
$\quad$ UK & 45 & 40 & 50 & 38.5 \\
$\quad$ Belgium & 51 & 22 & 43 & 33.9 \\
Lithuania & 52 & 29 & 21 & \\
South & & & & 32.6 \\
$\quad$ Spain & 40 & 27 & 31 & 26.0 \\
Italy & 39 & 20 & 35 & 15.4 \\
Portugal & 39 & 8 & 31 & \\
$\quad$ Greece & 18 & 14 & 14 & \\
\hline
\end{tabular}

Notes: Newspaper reach $=$ daily reach (in $\%$ ) in 2003. Newspaper ad share $=$ market share (in \%) of newspapers on advertising market in 2003. Internet penetration $=\%$ of people having access to the Internet in 2002. Market opportunities $=$ average of newspaper reach, newspaper ad share and internet penetration. Sources: Bundesamt für Statistiek (2006), European Commission (2002), FOS Gallup Europe (2002), and World Association of Newspapers (2004).

They reach a larger proportion of the population, capture a larger share of the advertising market, and serve a population with better Internet connections.

\section{Impact of market characteristics}

To assess the impact of these market differences on online newspaper content, we construct a market opportunities scale, defined as the average of newspaper reach, Internet penetration and newspaper share in advertising revenues (Cronbach's alpha $=.88$ ). We assume that market opportunities may influence the choice for business models, and that market opportunities and business models together shape online newspaper content, including the choice to provide frequently updated news or shovelware.

Correlation analysis confirms that market opportunities are to some extent related to business models. CRM newspapers are more strongly present in markets with better opportunities $(\mathrm{r}=.42 ; \mathrm{p}<.01)$. Crosstab analysis adds that there are particularly more CRM newspapers in the 
Table 6. Business models: Regional adoption and impact on type of online newspapers.

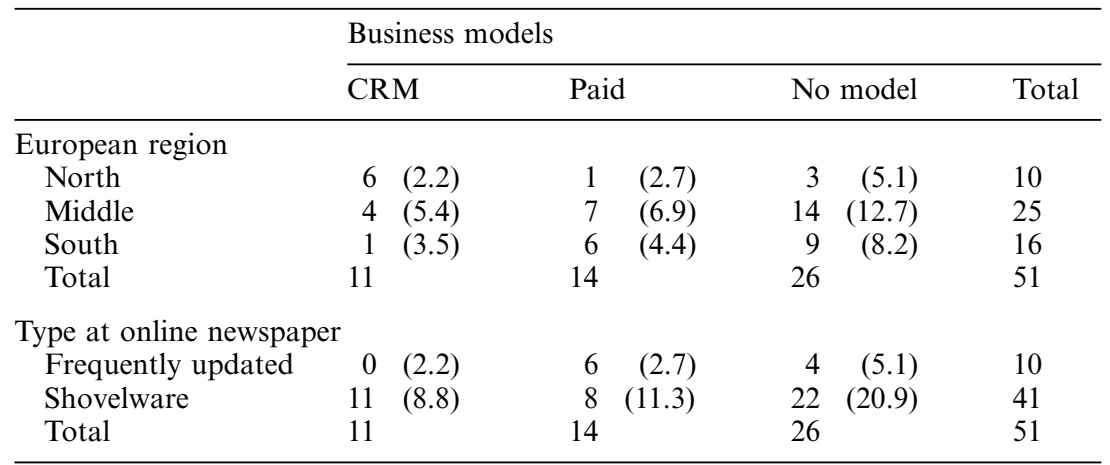

Notes: Values are numbers of newspapers. Expected values between brackets. Cramer's V (for business models * European regions) $=.339 ; \mathrm{p}<.05$. Cramer's V (for business models $*$ type of online newspapers $)=.391 ; \mathrm{p}<.05$.

North of Europe (see Table 6). Paid online newspapers on the other hand have a marginally stronger presence in the South, but the adoption of a paid model is not related to market opportunities $(r=-.084$; n.s.).

Business models, but not market opportunities, influence the choice to provide frequently updated news or shovelware. Controlling for differences in market opportunities, partial correlation analysis shows that frequently updated newspapers more frequently follow a paid content model (partial $\mathrm{r}=.307 ; \mathrm{p}<.05$ ) than a CRM model or no business model at all (see also Table 6). Frequently updated newspapers are, on the other hand, equally available in markets with different opportunities or, for that matter, in the North, Middle or South of Europe.

\section{Business models and online content}

Apart from the impact of business models on the choice for frequently updated news or shovelware, there are a few other differences between online newspapers with different business models. Controlling for the differences that we found between frequently updated and shovelware newspapers and for the impact of market opportunities, partial correlation analysis shows that paid newspapers offer more Internet features than other newspapers (see Table 7). They are more likely to offer sophisticated features as item-specific discussion forums, item-related opinion polls, internal hyperlinks, and audio files, as well as more simple item forward options. They score higher than other online newspapers on the user-user interactivity index, the hyperlinking index, and the content 
Table 7. Business models, market opportunities and online content (partial correlations).

\begin{tabular}{|c|c|c|c|}
\hline & \multicolumn{2}{|c|}{ Online business models } & \multirow{2}{*}{$\begin{array}{l}\text { Market } \\
\text { opportunities }\end{array}$} \\
\hline & Paid & CRM & \\
\hline \multicolumn{4}{|l|}{ News item variety indices } \\
\hline Topics & .015 & .013 & $.491 * *$ \\
\hline Geographic orientations & .004 & .028 & $.304^{\circ}$ \\
\hline \multicolumn{4}{|l|}{ Internet feature indices } \\
\hline Content selectivity & $.304^{\circ}$ & .080 & .083 \\
\hline Hyperlinks & $.332^{\circ}$ & .161 & .235 \\
\hline User-user interaction & $.494 * *$ & .100 & .261 \\
\hline Display ads on front page & .183 & .052 & $.456^{*}$ \\
\hline News items refer to print edition as source & .093 & .177 & $-.303^{\circ}$ \\
\hline \multicolumn{4}{|l|}{ Internet features } \\
\hline Hyperlinks to same online newspaper & $.367^{\circ}$ & .165 & .158 \\
\hline Author e-mail mentioned in item & .057 & .018 & $.487 * *$ \\
\hline Item-specific poll & $.320^{\circ}$ & .138 & -.265 \\
\hline Item forward option & $.308^{\circ}$ & .113 & $.362^{\circ}$ \\
\hline Item-specific forum & $.463 * *$ & .012 & .038 \\
\hline Audio files & $.306^{\circ}$ & .074 & -.025 \\
\hline
\end{tabular}

Notes: Partial correlations are controlled for differences between frequently updated and shovelware newspapers, and for differences in market opportunities (first and second column) or business models (third column). ${ }^{* *} \mathrm{p}<.001,{ }^{*} \mathrm{p}<.01$, or ${ }^{\circ}$ $\mathrm{p}<.05$.

selectivity index. Differences in content or news items, on the other hand, are almost absent.

The same lack of differences applies to CRM newspapers. CRM newspapers look very much like other online newspapers, not only in content and news item terms, but also in terms of Internet features. Because of the similarity in content and news item options, neither CRM nor paid newspapers add more unique content or news item options to the print offer than any other online newspaper. That is, online newspapers with different business models complement print editions in similar ways with content and news item options.

\section{Market opportunities and online content}

There are also a few differences between online newspapers produced under different market conditions. Again controlling for differences between frequently updated and shovelware newspapers and, this time, the impact of different business models, partial correlation analysis shows that online newspapers in markets with better opportunities report on a wider variety of topics and tend to offer a wider geographic variety of 
new items (see again Table 7). In addition, they are less inclined to use the print counterpart as source, more frequently add author e-mail addresses and item forward options to news items, and more frequently place display advertisements on the front page. Yet, like paid and CRM newspapers, online newspapers in markets with better opportunities do not complement print editions in significantly different ways with content or news items options than other online newspapers.

One final difference to be mentioned is that newspapers from the Middle of Europe are the least frequently updated newspapers. They score lower on the news item turnover index, offer more items that overlap with the print edition, and more overlapping items that are identical in the online and print editions (table not shown). Since we did not find significantly more shovelware newspapers in the Middle of Europe than elsewhere, these results indicate that shovelware newspapers in the Middle provide even less original news than shovelware newspapers in the North or South of Europe.

\section{Conclusions and discussion}

In 2003, print newspaper publishers had almost ten years experience with the Internet. Although some observers in the 1990s expected (or feared) that the Internet would rapidly replace print newspapers, the media evolutionary approach predicts that print newspapers and online news media will co-exist. Whether and in what form depends on how publishers deal with the dual challenge of, firstly, reconsidering the strengths and weaknesses of the print newspaper as mass-produced bundles of content in the light of new competitors; and secondly, developing online services that complement print newspapers and strengthen the competitive position of the newspaper brand.

To chart this media evolutionary process, we investigated and compared the characteristics of print and online newspapers. We focused on the front pages of the print and online editions of 51 serious national newspapers in Europe, as they were published on October 8, 2003. This focus undoubtedly brings its limitations. Important and popular newspapers, as tabloids, freesheets and regional newspapers were excluded and our investigation touched upon the surface of the investigated newspapers only. Yet, this focus was inevitable to make a comparison across 14 European countries and two media feasible.

\section{Modest complementarity}

Results show that European online newspapers complement print newspapers in modest ways. Almost all online front pages add interaction and 
communication elements and service information to the staple content categories of print newspapers (news, self-promotion and display advertising). Some online front pages emphasize other types of content, too. This makes online front pages more varied in content terms than print front pages. The most important difference, however, is that online front pages offer many more pointers. These findings indicate that online newspapers, compared with print newspapers, are more rather than less bundled products, that enable users to make their own individual selections of information and other types of content rather than presenting the news selection of the editors (Finnemann and Thomasen, 2005; Sparks and Yilmaz, 2005).

Research in the late 1990s showed that many online newspapers provided shovelware. This practice has changed to some extent. In 2003, the average online newspaper provides a considerable proportion of original, online-only news items. Apart from that, items that are taken from the print edition are to some extent adapted when they are put online. Online journalists nonetheless make very similar selections from a day's supply of newsworthy events and report on these events in very similar ways as print journalists. No clear editorial division of labour between print and online newspapers emerges from our analysis, except that online newspapers add news updates to the print news offer.

Research in the late 1990s likewise showed that online newspapers offered few Internet features. This has evolved, too. Online newspapers in 2003 complement print newspapers with content selection features and personal interactivity, as well as updated news. Multimedia, personalization and external hyperlinks, on the other hand, are as limited as before.

\section{No typology of online newspapers}

The online newspapers in our sample vary on different dimensions. Contrary to our expectations, these differences do not add up to a clear-cut typology of online newspapers that consistently provide more and less variety, or provide variety on clearly different dimensions.

The major distinction that emerges from the data and that makes intuitively sense is a distinction between frequently updated and shovelware newspapers. These newspapers emphasize different types of news items: brief, anonymous and frequently updated items that are unique to online editions in frequently updated newspapers; and factual news stories, copied from print editions, written by journalists and based on standard journalist sources in shovelware newspapers.

Another, potentially important distinction is between online newspapers that tend towards different business models. Paid online newspapers 
differ primarily from other newspapers because they offer more sophisticated Internet-specific features. CRM newspapers, on the other hand, are remarkably similar to other online newspapers, except that they require registration to access news, archives and classified ads. No differences exist between paid, CRM and other newspapers in the amount of advertising and self-promotion on front pages or in the labelling of print and online editions.

\section{Market opportunities}

CRM newspapers are more strongly present in the North than elsewhere. Paid newspapers, on the other hand, are more frequently found in the South than one would expect, given that print revenues and Internet penetration are lowest in the South. Online newspapers in the Middle of Europe, thirdly, produce more shovelware than online newspapers in other areas.

The CRM business model aims, by definition, at strengthening relationships with print subscribers. Intuitively, such a model fits better in the North where substantial numbers still subscribe to print newspapers. The data at the same time suggest that few additional features are considered necessary to draw audiences in the North online. Combined, these findings suggest that publishers and editors in the North may have the best opportunities but lack incentives to consider online newspapers a high priority, since print newspapers are not seriously threatened (yet). Newspapers in the Middle in contrast face a more difficult situation, with fewer opportunities and stronger threats. This may explain why many opt for a relatively cost-effective and therefore safe but also shortterm strategy of copying the print edition online. An explanation for the relatively strong presence of paid newspapers in the South, finally, might be that the serious national newspapers that we sampled serve a particular niche audience in the South that is highly interested in and consequently willing to pay for sophisticated online news.

The most striking finding, however, is that overall the analysis showed remarkably few differences between paid, CRM, and other online newspapers, and between online newspapers produced under different market conditions. Considering that we neither found any other clear distinctions or typologies, we conclude that most publishers and editors are still experimenting and that online newspapers still have to find their definite form and proper role in the European news market.

\section{Future developments}

The results allow us to make a few positive conclusions and conjectures regarding the future development of online newspapers. First, publishers 
so far have not unbundled newspapers. Even though unbundling is economically and technically feasible on the Internet, and even though publishers are confronted with new players that offer competitive unbundled products (e.g., electronic markets), online newspapers are, if anything, more bundled than print newspapers. Like print newspapers, online newspapers offer something for almost every one and every taste, thereby reducing costs; but unlike print newspapers enable users to make their own selections. Online newspapers thereby convert relatively easily one of the weak points of print newspapers, their lack of customization, into a strong point.

Secondly, the analysis indicates that the distinctive contribution of online newspapers increasingly consists of frequently updated news items and some user-user interaction. Other possible contributions, for example providing analysis and background information or multimedia, or emphasizing clearly different and complementary types of news and content, are not adopted. Arguably, frequently updated news and useruser interactivity better fit the newspaper tradition than providing different media or changing reporting practices. Besides, publishers can serve traditional news-interested audiences with online updates and interaction opportunities without having to fear that online activities cannibalize print revenues. Providing updated news and user-user interaction therefore allow a continued focus on the newspaper core businesses: providing news and creating audiences for advertisers.

\section{Future research}

Since 2003, online newspapers have further evolved. Designs have changed, sometimes more than once, and Web 2.0 features such as RSS feeds have been added. Experiments with user-generated content continue, but news and information still flow primarily from newspaper to reader. Weblogs for example, added to many online newspapers in our sample, are primarily journalist-written, not user-generated. An increasing number of news items is specifically produced for the online edition, either by online journalists or by journalists working in an integrated print and online newsroom. Business models, however, are as elusive as before and most online newspapers continue to be experiments rather than fully developed services that can keep their own.

Looking back at these developments, we might argue that online newspapers in 2003 still stood at the beginning of their evolution. Of course, the Internet diffused rapidly and thoroughly as infrastructure in the 1990s. Yet, in terms of content and services the Web seemed to have entered its innovation phase, defined as the phase where contents, new business models and innovative regulations are developed (Stöber, 2004), 
only in the early 2000s, signalled by the introduction of Web 2.0 and following the dot.com crisis of 2001. Hopefully, this study stimulates new international comparative analyses, using the same or a compatible content-analytical method, to trace the further development of online newspapers systematically in the years to come.

\section{Notes}

1. In this paper, 'serious' newspapers are defined as newspapers that emphasize journalistic standards; give ample space to traditional hard news (on politics and economics) next to human interest stories, entertainment and other 'soft' news; present 'hard' facts and opinions next to personalized stories and colour-writing; and they are generally seen as important contributors to the public sphere (Esser, 1999; Nice, 2007; Sparks, 2003). They include what others consider the prestige or quality press as well as some 'popular' newspapers (like De Telegraaf in the Netherlands), but exclude tabloids like The Sun and Bild.

2. The actual number depends on the number of available newspapers and their circulations.

3. Self-promotion is promotion for the newspaper or other products of the publisher.

4. Service information is information on other than current affairs, such as the weather forecast, book reviews and community information.

5. The number of options added by online to print editions equals the complementarity index times the number of options (in this case, $0.32 * 8=2.56$ ).6. Correlations between the levels of variety on different investigated dimensions are almost all weak and insignificant. Out of 91 correlations, 81 are not significant, 8 are significant at $\mathrm{p}<.05$, and only 2 are significant at $\mathrm{p}<.01$. These latter two correlations suggest that online newspapers that provide more topic variety also tend to provide more internal or external hyperlinks $(\mathrm{r}=.44 ; \mathrm{p}<.01)$, and that format variety goes with author variety $(\mathrm{r}=.40 ; \mathrm{p}<.01)$. Additional exploratory cluster and factor analyses likewise indicate no clear variety patterns or newspaper typologies.

\section{References}

Bardoel, J. (1996). Beyond journalism. A profession between information society and civil society. European Journal of Communication, 11(3), 283-302.

Boczkowski, P. J. (2002). The development and use of online newspapers: What research tells us and what we might want to know. In L. Lievrouw and S. Livingstone (Eds.), Handbook of New Media (pp. 270-286). London: Sage.

Bridges, J. A. and Bridges, L. W. (1997). Changes in news use on the front pages of the American daily newspaper, 1986-1993. Journalism and Mass Communication Quarterly, 74(4), 826-838.

Brook, S. (2006, February 27). One newspaper reader worth up to 100 online users in ad revenue. The Guardian. Retrieved November 13, 2006, from LexisNexisAcademic database

Chyi, H. I. and Lasorsa, D. (2002). An explorative study on the market relation between online and print newspapers. Journal of Media Economics, 15(2), 91-106.

Chyi, H. I. and Sylvie, G. (1998). Competing with whom? Where? And how? Journal of Media Economics, 11(2), 1-18.

Chyi, H. I. and Sylvie, G. (2000). Online newspapers in the U.S. Perceptions of markets, products, revenue, and competition. International Journal on Media Management, 2(2), 69-77. 
Cowen, N. (2001). The future of the British broadsheet newspaper on the World Wide Web. Aslib Proceedings, 53(5), 189-200.

Deleersnyder, B., Geyskens, I., Gielens, K., and Dekimpe, M. G. (2002). How cannibalistic is the Internet channel? A study of the newspaper industry in the United Kingdom and The Netherlands. International Journal of Research in Marketing, $19,337-348$.

Deuze, M. (2003). The web and its journalisms: considering the consequences of different types of media online. New Media and Society, 5(2), 203-230.

Dimitrova, D. V., Connolly-Ahern, C., Williams, A. P., Kaid, L. L., and Reid, A. (2003). Hyperlinking as gatekeeping: Online newspaper coverage of the execution of an American terrorist. Journalism Studies, 4(3), 401-414.

Dimmick, J. and Rothenbuhler, E. (1984). The theory of the niche: Quantifying competition among media interests. Journal of Communication, 34, 109-119.

Dimmick, J. W. (2003). Media competition and coexistence. The theory of the niche. Mahwah, NJ: Lawrence Erlbaum Accociates.

Esser, F. (1999). 'Tabloidization' of news. A comparative analysis of Anglo-American and German press journalism. European Journal of Communication, 14(3), $291-$ 324.

Evans, P. and Wurster, T. S. (2000). Blown to bits. Boston, MA: Harvard Business School Press.

Finnemann, N. O. and Thomasen, B. H. (2005). Denmark: Multiplying news. In R. van der Wurff and E. Lauf (Eds.), Print and online newspapers in Europe: A comparative analysis in 16 countries (pp. 91-103). Amsterdam: Het Spinhuis.

Glotz, P. (2004). Wandel in der Kontinuität. Herausforderungen an eine neue Zeitungskultur. In P. Glotz and R. Meyer-Lucht (Eds.), Online gegen Print. Zeitung und Zeitschrift im Wandel (pp. 11-25). Konstanz: UVK.

Grant, A. H. W. and Schlesinger, L. A. (1995). Realize your customer's full profit potential. Harvard Business Review, 73(5), 59-72.

Gustafsson, K.E. and Weibull, L. (1997). European newspaper readership: structure and development. European Journal of Communication Research, 22(3), 249-297.

Ha, L. and James, E. L. (1998). Interactivity reexamined: A baseline analysis of early business web sites. Journal of Broadcasting and Electronic Media, 42(4), 457-474.

Harvey, F. (2004, April 20). Screen presence. Online versions of newspapers can stretch brands but publishers are cagey about showing they have repaid their investments. The Financial Times, p. 12. Retrieved November 13, 2006, from LexisNexisAcademic database

Hayward, D. (2002, June 19). Curtain falls on 'longest free trial in history': online newspapers. The Financial Times, p. 2. Retrieved November 13, 2006, from LexisNexisAcademic database

Ihlström, C. and Palmer, J. (2002). Revenues for online newspapers: owner and user perceptions. Electronic Markets, 12(4), 228-236.

INMA (2006). INMA Brand Extension Seminar. Retrieved November 13, 2006, from http://www.inma.org/2006-barcelona-line-extensions.cfm

Jankowski, N. W. and Van Selm, M. (2000). Traditional news media online: An examination of added values. Communications, 25(1), 85-101.

Kenney, K., Gorelik, A., and Mwangi, S. (2000). Interactive features of online newspapers. First Monday, 5(1). Retrieved May 2004, from http://www.firstmonday.org/ issues/issue5_1/kenney/index.html

Kluver, A. R. (2002). The logic of new media in international affairs. New Media and Society, 4(4), 499-517.

Lasica, J. D. (1996). Net gain. American Journalism Review, 18(9), 20-33. 
Lehman-Wilzig, S. and Cohen-Avigdor, N. (2004). The natural life cycle of new media evolution - Inter-media struggle for survival in the internet age. New Media and Society, 6(6), 707-730.

Li, X. (1998). Web page design and graphic use of three US newspapers. Journalism and Mass Communication Quarterly, 75(2), 353-365.

Lin, C. A. and Jeffres, L. W. (2001). Comparing distinctions and similarities across websites of newspapers, radio stations, and television stations. Journalism and Mass Communication Quarterly, 78(3), 555-573.

Massey, B. L. and Levy, M. R. (1999). Interactivity, online journalism, and Englishlanguage web newspapers in Asia. Journalism and Mass Communication Quarterly, $76(1), 138-151$.

Matheson, D. (2004). Weblogs and the epistemology of the news: Some trends in online journalism. New Media and Society, 6(4), 443-468.

McQuail, D. (2005). McQuail's mass communication theory (5 $5^{\text {th }}$ ed.). London: Sage.

Mings, S. M. and White, P. B. (2000). Profiting from online news: The search for viable business models. In B. Kahin and H. R. Varian (Eds.), Internet publishing and beyond (pp. 62-96). Cambridge, MA: The MIT Press.

Neuberger, C., Tonnemacher, J., Biebl, M., and Duck, A. (1998). Online - The future of newspapers? Germany's dailies on the World Wide Web. Journal of Computer Mediated Communication, 4(1). Retrieved June 2004, from http://jcmc.indiana.edu/ vol4/issue1/neuberger.html

Newspaper Association of America (2006). The source. Newspapers by the numbers. Retrieved November 13, 2006, from Newspaper Association of America Web site: $\mathrm{http}: / /$ www.naa.org/thesource/the_source_newspapers_by_the_numbers.pdf

Nice, L. (2007). Tabloidization and the teen market. Journalism Studies, 8(1), 117-136.

O’Sullivan, J. (2005). Delivering Ireland: Journalism's search for a role online. Gazette, 67(1), 45-68.

Peng, F.Y., Tham, N.I., and Xiaoming, H. (1999). Trends in online newspapers: A look at the US web. Newspaper Research Journal, 20(2), 52-63.

Peter, J. and Lauf, E. (2002). Reliability in cross-national content analysis. Journalism and Mass Communication Quarterly, 79(4), 815-832.

Picard, R. G. (2000). Changing business models of online content services; their implications for multimedia and other content producers. The International Journal on Media Management, 2(2), 60-68.

Quinn, G. and Trench, B. (2002). Mudia - Online news media and their audiences. Maastricht: Infonomics. Retrieved June 2005, from http://mudia.ecdc.info/results/ WP1 $\% 20$ Del $\% 201.3 \% 20 \mathrm{Web}^{2} \% 20$ Version.pdf

Saksena, S. and Hollifield, C. A. (2002). U.S. newspapers and the development of online editions. International Journal on Media Management, 4(2), 75-84.

Schoenbach, K. (Ed.) (1997). Zeitungen in den Neunzigern: Faktoren ihres Erfolgs. Bonn: ZV Zeitungs-Verlag Service GmbH.

Schultz, T. (1999). Interactive options in online journalism: A content analysis of 100 U.S. newspapers. Journal of Computer Mediated Communication, 5(1). Retrieved May 2004, from http://jcmc.indiana.edu/vol5/issue1/schultz.html

Singer, J. B. (2001). The metro wide web: Changes in newspapers' gatekeeping role online. Journalism and Mass Communication Quarterly, 78(1), 65-80.

Sparks, C. (1999). Newspapers, the Internet and the public sphere. In Y. N. Zassoursky and E. Vartanova (Eds.), Media, Communications and the Open Society (pp. 88-104). Moscow: Faculty of Journalism/IKAR Publisher.

Sparks, C. (2003). The contribution of online newspapers to the public sphere: A United Kingdom case study. Trends in Communication, 11(2), 111-126. 
Sparks, C. and Yilmaz, A. (2005). United Kingdom: The triumph of quality? In R. van der Wurff and E. Lauf (Eds.), Print and online newspapers in Europe: A comparative analysis in 16 countries (pp. 259-273). Amsterdam: Het Spinhuis.

Stöber, R. (2004). What media evolution is. A theoretical approach to the history of new media. European Journal of Communication, 19(4), 483-505.

Van der Wurff, R. and Lauf, E. (2005a). COST A20 newspaper working group codebook. In R. van der Wurff and E. Lauf (Eds.), Print and online newspapers in Europe: A comparative analysis in 16 countries (pp. 289-318). Amsterdam: Het Spinhuis.

Van der Wurff, R. and Lauf, E. (Eds.) (2005b). Print and online newspapers in Europe: A comparative analysis in 16 countries. Amsterdam: Het Spinhuis.

Weber, J. (2006, October 3). Newspapers grapple with an unbundled world. Times Online. Retrieved November 2006, from http://technology.timesonline.co.uk/ article/0,,20411-2386875,00.html

Zürn, M. (2000). Print- und Onlinezeitungen im Vergleich. Media Perspektiven 7, 319-325. 